\title{
Molecular Dynamics Simulation on the Separation of Ethanol/Water in the New 6FDA/mODMS Membranes
}

\author{
Wei Zhao ${ }^{1, a}$, Wensheng Deng ${ }^{2, a}$, Zhipeng Zhao ${ }^{3, a}$, Miyi Li ${ }^{4, b}$, Zhiping Zhao ${ }^{5, a}$ \\ ${ }^{a}$ Beijing Institute of Technology, Beijing 100081, China
}

\begin{abstract}
It is well known that 4,4'- hexafluoro isopropylidene-phthalic anhydride(FDA) has higher permeability and selectivity. It is contributed to - CF group contained in polyimide structure material. In this study, the diffusion properties of a,w-bis(3-aminopropyldimethyl) oligodimethylsiloxane (ODMS) fragment impact on 6FDA were studied. Molecular simulation techniques and Grand canonical Monte Carlo(GCMC)calculations were adopted for predicting the permeability of $\mathrm{C}_{2} \mathrm{H}_{5} \mathrm{OH}$ and $\mathrm{H}_{2} \mathrm{O}$ in the three new polymers membranes. The membranes considered in this work were synthesized from 6FDA and ODMS. The sorption and diffusion properties of $\mathrm{C}_{2} \mathrm{H}_{5} \mathrm{OH}_{\text {and }} \mathrm{H}_{2} \mathrm{O}$ were calculated. The results show that the 6FDA/6ODMS presents higher permeability than 6FDA/2ODMS and 6FDA/4ODMS. With the longer of ODMS segments in the repeat units, the permeability and selectivity of $\mathrm{C}_{2} \mathrm{H}_{5} \mathrm{OH} / \mathrm{H}_{2} \mathrm{O}$ increase in the order of $6 \mathrm{FDA} / 2 \mathrm{ODMS}<$ $6 \mathrm{FDA} / 4 \mathrm{ODMS}<6 \mathrm{FDA} / 6 \mathrm{ODMS}$. The length of molecular chains becomes longer with the ODMS fragments increased, which leads to the gap between the molecular chains becoming larger. Due to the free volume in the system increases, it is more conducive to the larger molecular volume through the membrane. Hence, it can be predicted that the $6 \mathrm{FDA} / 6 \mathrm{ODMS}$ is the best for the separation of $\mathrm{C}_{2} \mathrm{H}_{5} \mathrm{OH} / \mathrm{H}_{2} \mathrm{O}$.
\end{abstract}

\section{Introduction}

Computer modeling of molecular systems at atomistic level has become a high-efficiency tool which is applied to study the membrane separation process ${ }^{[1-4]}$. Molecular dynamics (MD) simulation is an effective investigation approach for calculating the properties of polymeric microstructures ${ }^{[5-9]}$ after dynamic and equilibrium. Meanwhile, MD simulation has previously been used to study the membranes' permeability of gaseous mixture and organic liquid mixture. Liu et al. ${ }^{[10]}$ investigated the $\mathrm{CO}_{2} / \mathrm{CH}_{4}$ permeabilities in polyamide-imide isomers by molecular simulation. They found the 6FDA/12p exhibited higher diffusivity and permselectivity which were close to the reported experimental data. They also discussed the transport behavior of oxygen and nitrogen through organasilicon-containing polystyrenes by molecular simulation ${ }^{[11]}$. Zhou et al. ${ }^{[12]}$ studied the separation of water/ethanol azeotropic mixture in poly (vinyl alcohol) membrane by molecular simulation. For PVA membrane, they found that the conditions of room temperature and high pressure were favorable for separation. Finally, they concluded that the separation factor of PVA membrane with polymerization degree of 1000 can ensure the concentration of ethanol reaching $99.96 \mathrm{wt} \%$ under $298 \mathrm{~K}$ and $101.325 \mathrm{Kpa}$. Kuhn et al. ${ }^{[13]}$ investigated the adsorption and diffusion of water, methanol and ethanol in all-silica DD3R membrane. The simulated results were well agreement with the experimental data, too.

In order to make sure that using the molecular simulation method to calculate the diffusion coefficient is reliable, we repeated the work of Liu et al. ${ }^{[10,14]}$, at first. The diffusivity of $\mathrm{O}_{2}$ through the PDMS membrane was calculated by using Molecular dynamics (MD) simulation. Fortunately, the calculated value was well agreement with the experiment data ${ }^{[15,16]}$. In addition, the calculated value of solubility of $\mathrm{CO}_{2}$ in $6 \mathrm{FDA} / 8 \mathrm{~m}$ membrane was well agreement with the experiment data ${ }^{[17]}$. Therefore, it can be concluded that the MD simulation method was reasonable to predict the penetration behavior of molecules in membranes. The Molecular dynamics (MD) simulations are performed in this work to predict the permselectivity of $\mathrm{C}_{2} \mathrm{H}_{5} \mathrm{OH} / \mathrm{H}_{2} \mathrm{O}$ in three new polymer membranes which are based on 6FDA/mODMS $(\mathrm{m}=2,4$, 6). The Solubility and Diffusivity of the membranes were calculated and compared. Finally, the membrane composition will be found which is the most suitable for the separation of ethanol and water.

\section{Methodology}

The solution-diffusion mechanism ${ }^{[14]}$ is used to describe the permeation of small penetrant through nonporous polymeric membranes. It is worth to note that the permeability is the product of the diffusion coefficient $(D)$ and solubility coefficient $(S)$ which can be described as

$a_{A / B}=a_{d} \times a_{g}=\left(D_{A} / D_{B}\right) *\left(S_{A} / S_{B}\right)$

\subsection{Solubility}

The solubility coefficients of the penetrant molecules can be determined from the Grand Canonical Monte Carlo (GCMC) method. In addition, the concentration probability of penetrant in the membrane is determined by the energy change between the new configuration and the previous configuration. In this procedure, a Metropolis algorithm was used to decide on sorbate insertion and deletion as well as the acceptance or rejection of configurational moves (rotation and translation of the sorbate molecules $)^{[15]}$.

The dual-mode sorption model was illustrated to study the penetrant sorption behaviors from lower to higher pressure in this work, as the following equations ${ }^{[16-18]}$ described:

$C=k_{D} P+\frac{c_{H} b P}{1+b P}$
$S=\frac{c}{P}=k_{D}+\frac{c_{H} b}{1+b P}$ 
Where $C$ is the total penetrant concentration in a glassy polymer; $k_{D}$ is the Henry's law coefficient; $C_{H}$ and $b$ are the capacity parameter and the Langmuir hole affinity parameter, respectively; $S$ is the solubility of penetrant.

\subsection{Diffusion}

Diffusion coefficient is calculated by the Einstein's relationship ${ }^{[19]}$ :

$D=\lim _{t \rightarrow \infty} \frac{\left.\{r(t)-r(0)]^{2}\right\}}{6 t}$

Where $D$ is the self-diffusion coefficient, and $r(0)$ is an initial position vector of the penetrant molecules at time 0 , $r(t)$ is the position vectors of the penetrant molecule at time $t$. $\left\langle|r(t)-r(0)|^{2}\right\rangle$ represents the ensemble average of the mean-square displacement (MSD) of the inserted penetrant molecules.

\section{Models And Simulation Details}

\subsection{Models building}

The simulations were performed using Material Studio (MS) software 6.0 (Accelrys Inc., San Diego). The chemical structures of 6FDA and ODMS were constructed by the Amorphous Cell module showed in Fig.1. One polymer chain was folded in the amorphous cell under periodic boundary conditions at $318 \mathrm{~K}$ to get 10 independent configurations. Then, the configuration with lowest energy was selected for energy minimization. This task employed both steepest descent and conjugate gradient algorithms with the convergence level setting to $0.001 \mathrm{kcal} \cdot \mathrm{mol}^{-1} \cdot \AA^{-1}$. In order to reach the equilibration, these structures were subjected to anneal simulation with the NPT ensemble at $1 \mathrm{~atm}$. The cells were heated from $200 \mathrm{~K}$ to $800 \mathrm{~K}$ and then cooled down from $800 \mathrm{~K}$ to 200 $\mathrm{K}$ with the gradient of $50 \mathrm{~K}$. At each step, $120 \mathrm{ps}$ NPT MD simulation were carried out. After that, 150 ps NPT MD simulation were performed to further optimize the structures. Finally, $1.5 \mathrm{~ns}$ NVT MD simulation were performed for analyzing the properties of the membranes.

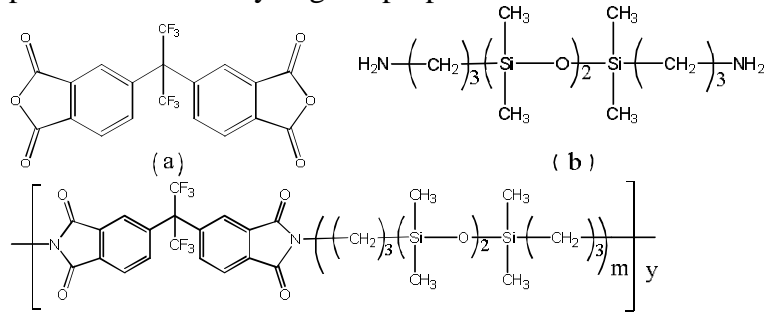

(c)

Figure 1. Represents the repeat units of the polymers used in this study, (a):6FDA, (b): OMDS, (c) the repeat unit of product, $\mathrm{m}=2,4,6$.

In this study the COMPASS force field ${ }^{[20-22]}$ was used which shows efficient in reproducing density-related properties in polymers ${ }^{[23]}$. The non-bonded interactions were calculated by using the Van der Waals and Coulombic interactions. The "atom based" method ${ }^{[24]}$ was used with a cutoff distance of $9.5 \AA$. The spine width and buffer width were $1.00 \AA$ and $0.5 \AA$, respectively. All the procedures were given the same step of 1 fs. The Andersen thermostat was used for temperature and the Bendersen was used for pressure control. In order to avoid packing algorithm related catenations and spearing of aromatic units it was necessary to start with a low initial packing density (typically $0.1 \mathrm{~g} / \mathrm{cc}^{[25]}$ ).

\subsection{Simulation of solubility and diffusivity}

The solubility of $\mathrm{H}_{2} \mathrm{O}$ and $\mathrm{C}_{2} \mathrm{H}_{5} \mathrm{OH}$ were calculated by using the GCMC (Grand Canonical Monte Carlo) method $^{[26,27]}$. The sorption isotherm was obtained by using Sorption modules over a pressure range 10-500 $\mathrm{KPa}$. At each pressure, 1000000 steps of GCMC calculations were performed by using an initial equilibration period of 100000 steps.

Diffusivities were obtained by the addition of 20 water and 1 ethanol molecules into each independently equilibrated configuration to form a new simulation cell at $318 \mathrm{~K}$. Then, the same procedure that described in Section 3.1 was used after each configuration equilibrated. The diffusion simulations were performed for $3.5 \mathrm{~ns}$ under the NVT ensemble. Finally, an average value of $D$ was obtained from the independent states.

\section{Results And Discussion}

There are two empirical standards can prove the final equilibrium structures are obtained, that is the variation magnitude of temperature with time within $10 \%$, the same as the energy. As can be seen from the Fig.2, both the ranges of change of the temperature and the energy are within 5\%. Therefore, the final structures obtained after MD simulation were effective when they were used to analyze the data.


Figure 2. Energy vs. simulation time(a)Nonbond energy; (b)Potential energy,and Temperature vs. simulation time.

\subsection{Solubility}

The sorption isotherms of the 6FDA/2ODMS, 6FDA/4ODMS and 6FDA/6ODMS are shown in Fig.3. With the help of Eq. (2) and Eq. (3), the water solubility and ethanol solubility of the polymers can calculate. All the results are listed in Table 1. By the Eq. (1), the solubility selectivity can be obtained. According to Table $\mathbf{1}$, it is found that there is no significant difference among the water solubility in each polymer. The values of ethanol solubility in 6FDA/2ODMS and 6FDA/4ODMS are almost same, but the ethanol solubility in 6FDA/6ODMS is higher than these two. 


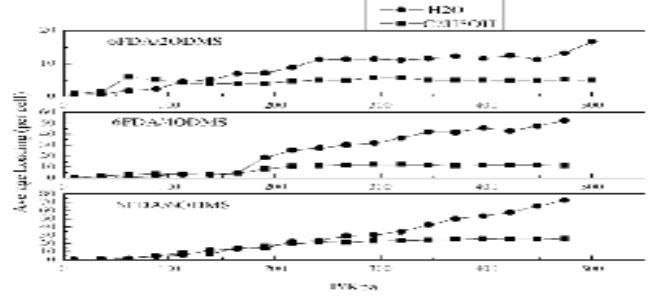

Figure 3. Represents the sorption isotherm of $\mathrm{C}_{2} \mathrm{H}_{5} \mathrm{OH}$ and $\mathrm{H}_{2} \mathrm{O}$ in $6 \mathrm{FDA} / \mathrm{mODMS}(\mathrm{m}=2,4,6)$.

\subsection{Diffusivity}

All the results of diffusion coefficients are listed in Table 1. The $\log (\mathrm{MSD})$ dependence of $\log$ (time) of $\mathrm{C}_{2} \mathrm{H}_{5} \mathrm{OH}$ and $\mathrm{H}_{2} \mathrm{O}$ molecules in 6FDA/2ODMS, 6FDA/4ODMS and 6FDA/6ODMS are presented in Fig.4. The criterion for a model system reaching the normal diffusion regime is that the slope of $\log (\mathrm{MSD})$ vs. $\log (\mathrm{t})$ approaches unity $^{[28-30]}$. Note that the slope of the $\log (\mathrm{MSD})$ vs. $\log (\mathrm{t})$ curve increases approximately after 1500 ps for $\mathrm{H}_{2} \mathrm{O}$ and $\mathrm{C}_{2} \mathrm{H}_{5} \mathrm{OH}$ in 6FDA/2ODMS, after 800 ps for $\mathrm{H}_{2} \mathrm{O}$ and $\mathrm{C}_{2} \mathrm{H}_{5} \mathrm{OH}$ in 6FDA/4ODMS, after 1000 ps for $\mathrm{H}_{2} \mathrm{O}$ and $\mathrm{C}_{2} \mathrm{H}_{5} \mathrm{OH}$ in 6FDA/6ODMS, respectively. In Fig.5, the Mean-square displacements of $\mathrm{H}_{2} \mathrm{O}$ and $\mathrm{C}_{2} \mathrm{H}_{5} \mathrm{OH}$ in 6FDA/2ODMS, 6FDA/4ODMS, 6FDA/6ODMS are listed in Table 1.
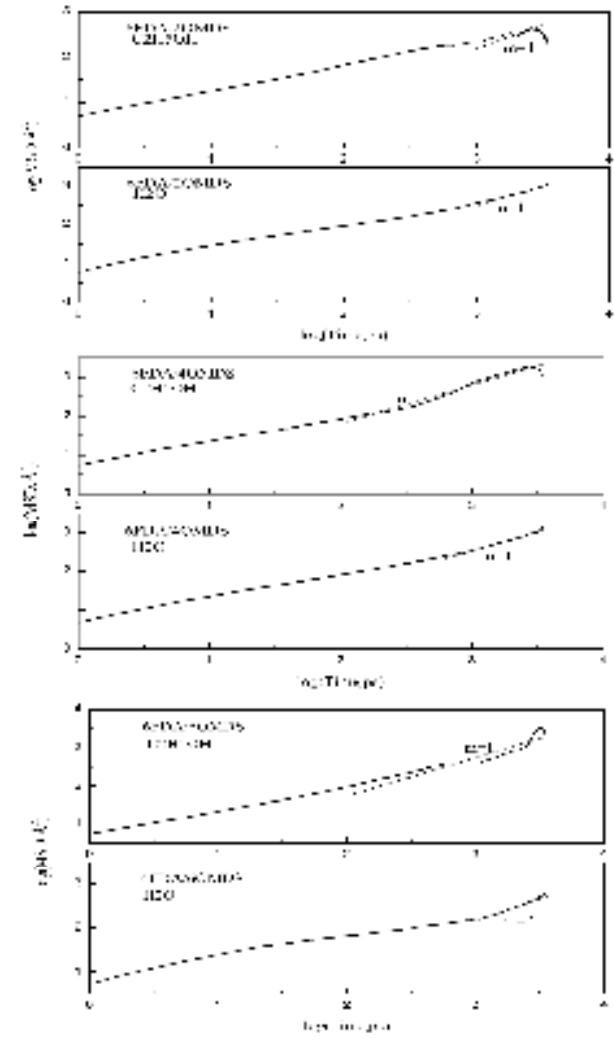

Figure 4. $\log (\mathrm{MSD})$ vs. $\log (\mathrm{t})$ plots for the diffusion of $\mathrm{C}_{2} \mathrm{H}_{5} \mathrm{OH}$ and $\mathrm{H}_{2} \mathrm{O}$ in the $6 \mathrm{FDA} / \mathrm{mODMS}(\mathrm{m}=2,4,6)$.
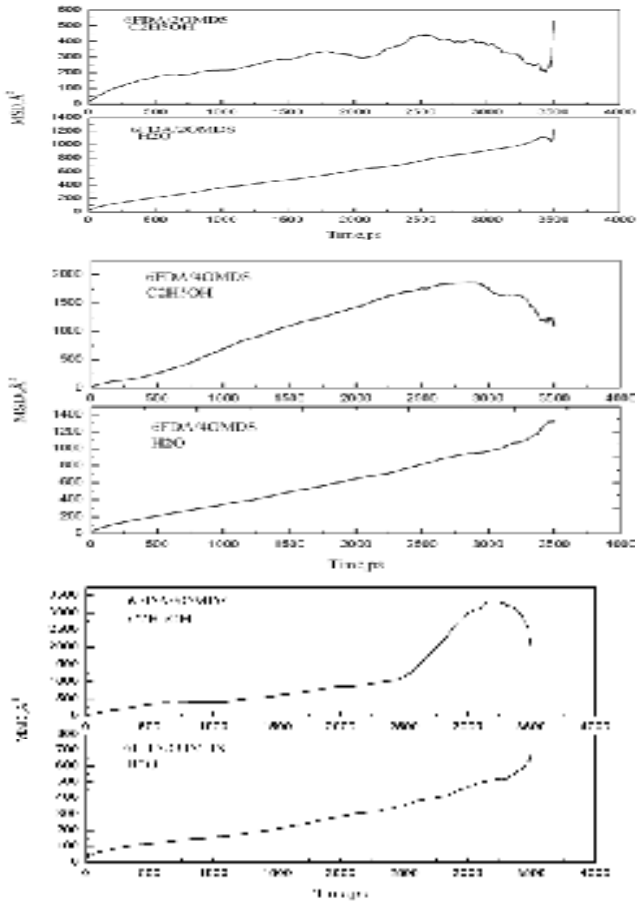

Figure 5. Represents the MSD of $\mathrm{C}_{2} \mathrm{H}_{5} \mathrm{OH}$ and $\mathrm{H}_{2} \mathrm{O}$ in the $6 \mathrm{FDA} / \mathrm{mODMS}(\mathrm{m}=2,4,6)$.

According to Table 1, viewed that there is no significant difference between the water diffusivity in 6FDA/2ODMS and 6FDA/4ODMS, however, the water diffusivity in 6FDA/6ODMS is smaller than these two. It is found that the diffusivity of $\mathrm{C}_{2} \mathrm{H}_{5} \mathrm{OH}$ in the polymers increases in the order of 6FDA/2ODMS < 6FDA/4ODMS <6FDA/6ODMS. Absolutely, the diffusion selectivity of 6FDA/6ODMS is the largest.

The permselectivity can be calculated with Eq. (1), as listed in Table 1. It is found that the higher permselectivity of $6 \mathrm{FDA} / 6 \mathrm{ODMS}$ is mainly due to its higher diffusivity selectivity. Also it can be found that with the increasing of ODMS segments in the repeat units,

the $a_{C_{2} H_{Z} O H / H_{2} O}$ for the polymers increase in the order of $6 \mathrm{FDA} / 2 \mathrm{ODMS}<6 \mathrm{FDA} / 4 \mathrm{ODMS}<6 \mathrm{FDA} / 6 \mathrm{ODMS}$. The permeability in the polymers has relationship with the molecular dimension of penetrant and the free volume of the polymers. As we known, $\mathrm{C}_{2} \mathrm{H}_{5} \mathrm{OH}$ has larger dimension and smaller free volume than $\mathrm{H}_{2} \mathrm{O}$. With the increasing of ODMS segment in the repeat units, the free volume of the polymers increase, which lead to the permeability of $\mathrm{C}_{2} \mathrm{H}_{5} \mathrm{OH}$ in the polymer becoming larger. As the results shown in Table 1, the polymer 6FDA/6ODMS has the best permselectivity. 
Table 1. solubility, diffusivity and selectivity values for $\mathrm{C}_{2} \mathrm{H}_{5} \mathrm{OH}$ and $\mathrm{H}_{2} \mathrm{O}$ in 6FDA/2ODMS, 6FDA/4ODMS and 6FDA/6ODMS at 318K. (A and $\mathrm{B}$ respectively represent $\mathrm{C}_{2} \mathrm{H}_{5} \mathrm{OH}$ and $\mathrm{H}_{2} \mathrm{O}$ ).

\begin{tabular}{llll}
\hline & 6FDA/2ODMS & 6FDA/4ODMS & 6FDA/6ODMS \\
\hline $\mathrm{S}_{\mathrm{A}} * 10^{2} /\left(\mathrm{cm}^{3}(\mathrm{STP}) \cdot \mathrm{cm}^{-3} \cdot \mathrm{atm}^{-1}\right)$ & 2.6470 & 2.6040 & 6.1180 \\
$\mathrm{~S}_{\mathrm{B}} * 10^{2} /\left(\mathrm{cm}^{3}(\mathrm{STP}) \cdot \mathrm{cm}^{-3} \cdot \mathrm{atm}^{-1}\right)$ & 0.8586 & 0.9310 & 0.7596 \\
$\alpha_{s}=S_{A} / S_{B}$ & 3.08 & 2.80 & 8.05 \\
$\mathrm{D}_{\mathrm{A}} * 10^{6} /\left(\mathrm{cm}^{2} \cdot \mathrm{s}^{-1}\right)$ & 2.937 & 8.983 & 14.756 \\
$\mathrm{D}_{\mathrm{B}} * 10^{6} /\left(\mathrm{cm}^{2} \cdot \mathrm{s}^{-1}\right)$ & 5.218 & 5.74 & 2.295 \\
$\alpha_{d}=D_{A} / D_{B}$ & 0.563 & 1.57 & 6.43 \\
$\alpha_{A / B}=\alpha_{s} \cdot \alpha_{d}$ & 1.73 & 4.40 & 51.7 \\
\hline
\end{tabular}

\section{Conclusions}

Molecular dynamics simulations based on the COMPASS forcefield have been performed to study the permeability of $\mathrm{C}_{2} \mathrm{H}_{5} \mathrm{OH} / \mathrm{H}_{2} \mathrm{O}$ in 6FDA/2ODMS, 6FDA/4ODMS and 6FDA/6ODMS. The sorption and diffusion properties of $\mathrm{C}_{2} \mathrm{H}_{5} \mathrm{OH} / \mathrm{H}_{2} \mathrm{O}$ in the polymers are investigated. It is found that the solubility and diffusivity of $\mathrm{H}_{2} \mathrm{O}$ in 6FDA/6ODMS have smaller values than the other two, and the solubility and diffusivity $\mathrm{C}_{2} \mathrm{H}_{5} \mathrm{OH}$ in 6FDA/6ODMS have greater values than the other two. Therefore, it can be obtained that the polymer 6FDA/6ODMS has the greater permselectivity of $\mathrm{C}_{2} \mathrm{H}_{5} \mathrm{OH} / \mathrm{H}_{2} \mathrm{O}$ which is good for the separation of $\mathrm{C}_{2} \mathrm{H}_{5} \mathrm{OH}$ and $\mathrm{H}_{2} \mathrm{O}$.

\section{Acknowledgment}

This work is supported by the Youth Foundation of Natural Science Foundation of China (GN: 21206010).

\section{References}

[1] F.S Pan, J. Ma, L. Cui, Z.Y Jiang, Chem. Eng. Sci. 64(2009) 5192-5197.

[2] J.Y Wu, Q.L Liu, Y. Xiong, A.M Zhu, Y. Chen, J. Phys. Chem. B. 113(2009) 4267-4274.

[3] T. Pramananda Perumal, V. Sridhar, K.P.N. Murthy, K.S. Easwarakumar, S. Ramasamy, Comp. Mater. Sci. 38(2007) 865-872.

[4] C.H Lu, S.J Ni, W.K Chen, J.S Liao, C.J Zhang, Comp. Mater. Sci. 49(2010) 565-569.

[5] Wolfgang Paul, Polymer, 45(2004) 3901-3905.

[6] K.S Chang, Z.C Wu, S. Kim, K.L Tung, J. Membr. Sci. 454(2014) 1-11.

[7] M. Rahmati, H. Modarress, Reza Gooya, Polymer. 53(2012) 1939-1950.

[8] L.H Zhao, F.H Tian, X.B Wang, W.W Zhao, A.P Fu, Y.Y Shen, S.G Chen, S.Q Yu, Comp. Mater. Sci. 79(2013) 691-697.
[9] S.X Pan, Y.F Hu, Q. Li, Comp. Mater. Sci. 79(2013) 611-618.

[10] Y. Chen, Q.L Liu, A.M Zhu, Q.G Zhang, J.Y Wu, J. Membr. Sci. 348(2010) 204-212.

[11] Q.L Liu, Y. Huang, J. Phys. Chem. B. 110 (2006) 17375-17328.

[12] Z.W Qiao, Y.L Wu, X.W Li, J. Zhou, Fluid Phase Equilibr. 302(2011) 14-20.

[13] J. Kuhn, J. Gascon, S. Calero, J. Gross, J. Phys. Chem. C. 113(2009) 14290-14301.

[14] Y. Huang, Q.L Liu, Journal of Xiamen University (Natural Science). 45(2006) 664-669.

[15] S.G Charati, S.A Stern, Macromolecules. 31(1998) 5529-5535.

[16] Stern S.A, J. Membr. Sci. 94(1994) 1-65.

[17] Z.K Xu, M. Böhning, J. Springer, Polymer. 38(1997) 581-588.

[18] R.W. Baker, John Wiley \& Sons, Ltd. CA, (2004) 491-522.

[19] N. Metropolis, A.W. Resenbluth, M.N. Rosenbluth, A.H. Teller, E. Teller, J. Chem. Phys. 21 (1953) 1087-1109.

[20] W.R. Vieth, K.J. Sladek, J. Colloid Sci. 20 (1965) 1014-1033.

[21] D.R. Paul, W.J. Koros, J. Polym. Sci. Polym. Phys. Ed. 14(1976) 675-685.

[22] S. Kanehashi, K. Nagai, J. Membr. Sci. 253(2005)117-138.

[23] X.Y. Wang, A.J. Hill, B.D. Freeman, I.C. Sanchez, J. Membr. Sci. 314 (2008) 15-23.

[24] H. Sun, J. Phys. Chem. B 102 (1998) 7338-7364.

[25] H. Sun, J. Comput. Chem. 15 (1995) 752-768.

[26] H. Sun, P. Ren, J.R. Fried, Comput. Theor. Polym. Sci. 8 (1998) 229-246.

[27] M. Heuchel, D. Hofmann, P. Pullumbi, Macromolecules. 37 (2004) 201-214.

[28] P.V.K. Pant, R.H. Boyd, Macromolecules. 25 (1992) 494-495.

[29] Takeuchi H, J. Chem. Phys. 1990; 93:2062-2067.

[30] T. Liang, X. Zhang, J. Polym. Sci. Part B: Polym. Phys. 39(2001) 2243-2251. 